\title{
Short communication: Strengthening risk communication and community engagement for the containment of the Corona Virus Disease 2019 outbreak
}

\author{
Saurabh RamBihariLal Shrivastava, Prateek Saurabh Shrivastava
}

\begin{abstract}
Department of Community Medicine, Shri Sathya Sai Medical College \& Research Institute, Sri Balaji Vidyapeeth (SBV) - Deemed to be University, Ammapettai, Nellikuppam, Chengalpet District, Tamil Nadu - 603108.
\end{abstract}

\begin{abstract}
Objectives: The objective of the article is to understand the need and importance of risk communication and community engagement in containing the COVID-19 outbreak.

Introduction: The Corona Virus Disease-2019 (COVID-19) outbreak, which has been designated as a public health emergency of international concern has created a sense of fear and apprehension among the community across the world.

Methods: Acknowledging all these alarming facts, we cannot deny that we have to intensify our efforts and all the national policy makers should recognize the infection as of utmost public health priority and be prepared to respond to the potential outbreak within their own boundaries.

Results: Based on the earlier outbreaks of the infectious diseases in the current decades, risk communication and community engagement have been identified as one of the crucial and integral elements of a successful response to the public health emergencies.

Conclusion: In conclusion, risk communication and community engagement are an essential and challenging aspects of the containment of the COVID-19 outbreak and thus we have to try our best to establish a better system to ensure that risk communication is well in place and utilized effectively to engage the community.

Keywords: COVID-19 outbreak, public health emergency of international concern, risk communication, community engagement, World Health Organization.

DOI: https://dx.doi.org/10.4314/ahs.v20i3.18

Cite as: Shrivastava SRBL, Shrivastava PS. Short communication: strengthening risk communication and community engagement for the containment of the Corona Virus Disease 2019 outbreak. Afri Health Sci.2020;20(3): 1164-1165. https://dx.doi.org/10.4314/ahs. $v 20 i 3.18$
\end{abstract}

Dear Editor,

The Corona Virus Disease-2019 (COVID-19) outbreak, which has been designated as a public health emergency of international concern has created a sense of fear and apprehension among the community across the world. ${ }^{1}$ The disease continues to be on the rise each day and spread in nations other than China, with Egypt being

\section{Corresponding author:}

Saurabh RamBihariLal Shrivastava, Department of Community Medicine, Shri Sathya Sai Medical College \& Research Institute, Sri Balaji Vidyapeeth (SBV) - Deemed to be University, Tiruporur - Guduvancherry Main Road, Ammapettai, Nellikuppam, Chengalpet District, Tamil Nadu - 603108, India

Telephone number: +919884227224

Email: drshrishri2008@gmail.com the most recent nation, wherein 1 case of the disease has been detected, and it takes the toll to 25 nations. ${ }^{2}$ The available estimates released on 15 February 2020 revealed that a total of 50580 cases and 1526 deaths have been attributed to the disease. It is noteworthy that out of the total reported caseload 526 cases have been reported outside China, of which 170 confirmed cases have come out with a past history of travel to China. ${ }^{2}$ From the public health perspective, the situation is of serious magnitude, predominantly due to the lack of preparedness in most of the other non-affected nations and also because despite the institution of dedicated measures, the number of reported cases in China continues to rise each day. ${ }^{2,3}$ Furthermore, we are not very certain about the various attributes of the disease or the infection, which makes the overall containment process based on our previous experiences with earlier similar types of viruses in the past. ${ }^{1,3}$ At the same time, a lot needs to be done on the research front to en-

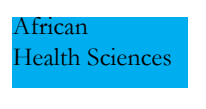

(C) 2020 Shrivastava SRBL et al. Licensee African Health Sciences. This is an Open Access article distributed under the terms of the Creative commons Attribution License (https://creativecommons.org/licenses/BY/4.0), which permits unrestricted use, distribution, and reproduction in any medium, provided the original work is properly cited. 
sure that we are soon ready with the potential vaccine, therapeutic approaches and specific strategies for the prevention and interruption of the transmission of the human-to-human infection. ${ }^{3}$

Acknowledging all these alarming facts, we cannot deny that we have to intensify our efforts and all the national policy makers should recognize the infection as of utmost public health priority and be prepared to respond to the potential outbreak within their own boundaries. ${ }^{1-4}$ Based on the earlier outbreaks of the infectious diseases in the current decades, risk communication and community engagement have been identified as one of the crucial and integral eleents of a successful response to the public health emergencies. ${ }^{4}$ The domain of risk communication and community engagement becomes extremely crucial, as any failure on that part can precipitate loss of trust, fear, financial consequences, emergence of wrong messages in the social media and eventually loss of property and lives.,

The need of the hour is to proactively inform the community about what do we know and what we don't know about the infection and what all we have been trying to know more about the infection with an aim to avoid untoward events and saving human lives. ${ }^{4}$ This has to be executed as it is the right of the people to know and understand the risk of the infection so that they can take appropriate steps to safeguard the lives of their near and dear ones. At the same time, we cannot deny the fact that the risk perception about the infection varies between different segments of the community and thus any proactive intervention from the health sector side can bridge the existing gaps and clear uncertainty. The effective delivery of risk communication and community engagement not only plays an important role in reducing the risk of infodemics or suppression of myths \& misunderstandings, but also creates a sense of trust in the community. ${ }^{1,4}$ This further enables better containment of the infection, as it indirectly strengthens the other disease control strategies, namely active surveillance, case reporting, contact tracing, provision of care to the sick individuals at various levels, etc., primarily because all these activities require community involvement. ${ }^{3,4}$ Further, we can succeed in averting any further social disruptions or amplification of outbreaks, as we will be in a better position to implement acceptable and useful interventions in the affected regions. ${ }^{4}$

\section{Conclusion}

Risk communication and community engagement are an essential and challenging aspects of the containment of the COVID-19 outbreak and thus we have to try our best to establish a better system to ensure that risk communication is well in place and utilized effectively to engage the community.

\section{Source of support}

None.

\section{Conflicts of interest}

None to be declared.

\section{References}

1. World Health Organization. Statement on the second meeting of the International Health Regulations (2005) Emergency Committee regarding the outbreak of novel coronavirus (2019-nCoV); 2020. https://www.who.int/ news-room/detail/30-01-2020-statement-on-the-second-meeting-of-the-international-health-regulations(2005)-emergency-committee-regarding-the-outbreakof-novel-coronavirus-(2019-ncov)

2. World Health Organization. Coronavirus disease 2019 (COVID-19) Situation Report - 26; 2020. Available from: https://www.who.int/docs/default-source/ coronaviruse/situation-reports / 20200215 -sitrep-26-covid-19.pdf?sfvrsn=a4cc6787_2

3. World Health Organization. 2019 Novel Coronavirus $(2019 \mathrm{nCoV})$ : Strategic preparedness and response plan. Geneva: WHO press; 2020.

4. World Health Organization. Risk communication and community engagement (RCCE) readiness and response to the 2019 novel coronavirus (2019-nCoV) Interim guidance v2. Geneva: WHO press; p: 1-3. 